\title{
A educação em tempo integral na meta 6 do plano estadual de educação do Pará
}

\author{
Full-time education in goal 6 of the Pará state education plan
}

\section{Educación de tiempo integral en la meta 6 del plan de educación del estado de Pará}

\begin{abstract}
Ney Cristina Monteiro de Oliveira'
Núcleo de Estudos Transdisciplinares em Educação Básica da Universidade Federal do Pará, Instituto de Ciências da Educação, Professora Titular.

http://orcid.org/0000-0002-8091-5213

\section{Elisângela Alves da Silua Scaff ${ }^{2}$}

Universidade Federal do Paraná, Departamento de Planejamento e Administração Escolar, Professora Associada.

http://orcid.org/0000000276820879
\end{abstract}

Resumo: Este artigo é fruto de análises sobre a política de implantação da escola de tempo integral na educação brasileira a partir de direcionamentos do governo federal e do governo estadual paraense a partir do Plano Estadual de Educação do Pará (PEE-PA). A investigação se configurou como pesquisa com abordagem qualitativa, realizada por meio de revisão bibliográfica e de pesquisa documental, tendo como objetivo geral analisar o Plano Estadual de Educação do Pará (Lei n 8.186/2015) e a implementação da sua Meta 6. 0 aporte teórico-metodológico deste estudo se inscreve no campo em que as poĺticas públicas são processo e produto que envolvem articulações entre textos e processos, com negociações constituidas de valores, ideologias, poder e contradições. Tem abordagem no ciclo de políticas proposto por Stephen J. Ball e Mainardes (2011), ao considerar o processo de formulação de poĺticas como um ciclo contínuo no qual as poĺticas são formuladas e recriadas. Para efeito deste artigo aproximamo-nos da perspectiva da análise do contexto e da produção do texto ao examinar o conteúdo da política e das proposições que a fundamentaram, os objetivos declarados nos documentos oficiais, bem como as ideias e conceitos explicitados nos Planos de Educação e resoluções aprovadas no estado do Pará. 0 estudo revelou que as concepções de tempo integral do PEE/PA são frágeis e não oferecem segurança teórico-metodológica para a política pretendida, além disso as estratégias declaradas e os procedimentos adotados não foram suficientes para atestar o sucesso e o alcance da Meta 6 no estado do Pará. Palavras-chave: Educação integral. Tempo integral. Plano Estadual de Educação. Pará.

\footnotetext{
Pós-doutora pelo Programa de Pós-graduação em Educação da Universidade Federal do Paraná; Doutora em Educação (Currículo) pela Pontifícia Universidade Católica de São Paulo.

2 Pós-doutora pela Universidade de São Paulo; Doutora em Educação pela Universidade de São Paulo.
} 
Abstract: This article is result of analyzes on the policy of implementing the full-time school in Brazilian education based on directions from the federal government and the state government of Pará based on the Pará State Education Plan (PEE-PA). The investigation was configured as research with a qualitative approach, conducted through literature review and documentary research, with the overall objective to analyze the Pará state Education Plan (Law n'. $8.186 / 2015$ ) and the implementation of its Goal 6. The theoretical-methodological contribution of this study is part of the field in which public policies are a process and a product that involve articulations between texts and processes, with negotiations consisting of values, ideologies, power and contradictions. The research presents an approach in the policy cycle proposed by Stephen J. Ball and Mainardes (2011), when considering the policy formulation process as a continuous cycle in which policies are formulated and recreated. For purposes of this article we approach the perspective of the analysis of the context and text production to examine the contents of the policy and propositions which it is based the objectives stated in the official documents, as well as the ideas and concepts explained in Education Plans and resolutions approved in Pará state. The research revealed that the full-time conceptions of the PEE/PA are fragile and do not offer theoretical and methodological security for the intended policy, in addition, the declared strategies and the adopted procedures were not enough to attest to the success and the achievement of Goal 6 in the Pará state

Keywords: Full-Time education. Full-time school. Pará State Education Plan..

Resumen: Este artículo es el resultado de análisis sobre la política de implementación de la escuela de tiempo integral en la educación brasileña con base en las instrucciones del gobierno federal y del gobierno estatal de Pará con base en el Plan Estatal de Educación de Pará (PEE-PA). La investigación se configuró como una investigación con enfoque cualitativo, realizada a través de revisión bibliográfica e investigación documental, con el objetivo general de analizar el Plan Estatal de Educación de Pará (Ley $n^{\circ} 8.186$ / 2015) y la implementación de su Meta 6. La contribución Los aspectos teóricos y metodológicos de este estudio son parte del campo en el que las políticas públicas son un proceso $y$ un producto que implica articulaciones entre textos y procesos, con negociaciones formadas por valores, ideologías, poder y contradicciones. Se aproxima al ciclo de políticas propuesto por Stephen J. Ball y Mainardes (2011), al considerar el proceso de formulación de políticas como un ciclo continuo en el que las politicas se formulan y recrean. $A$ los efectos de este artículo, abordamos la perspectiva de analizar el contexto y producir el texto examinando el contenido de la política y las propuestas que la sustentaron, los objetivos establecidos en los documentos oficiales, así como las ideas y conceptos explicados en los Planes de Educación y resoluciones aprobadas en el estado de Pará. El estudio reveló que las concepciones de tiempo integral del PEE / PA son frágiles y no ofrecen seguridad teórica y metodológica para la política pretendida, además las estrategias declaradas y los procedimientos adoptados no fueron suficientes para dar fe del éxito y el logro del Objetivo 6 en el estado de Pará.

Palabras clave: Educación integral. Tiempo integral. Plan de Educación del Estado de Pará. 


\section{ESTUDO DOS PLANOS DE EDUCAÇÃO NO CENÁRIO DA POLIITICA EDUCACIONAL PARAENSE: APRESENTANDO $O$ DEBATE}

Este artigo se vincula à necessidade de aprofundar as análises sobre a efetividade da política de implantação da escola de tempo integral no estado do Pará, para tanto focalizamos o estudo do Plano Estadual do Pará/2015 com vistas a compreender as concepções e estratégias adotadas para o alcance da Meta 6 do PNE/2014 e PEE-PA/2015, o processo de planejamento e o acompanhamento da oferta da escola em tempo integral.

Apresento aqui uma fase da investigação “A Educação em Tempo Integral na Meta 6: Concepções e Estratégias Reveladas no Plano Estadual de Educação do Pará", realizada no período de 2019/2020, uma pesquisa com abordagem qualitativa, realizada por meio de revisão bibliográfica e de pesquisa documental, tendo como objetivo geral analisar o processo de monitoramento do Plano Estadual de Educação do Pará (Lei n 8.186/2015) com vistas a discutir a efetivação de suas metas, em especial, a Meta 6 do Plano Nacional de Educação (PNE): “Oferecer educação em tempo integral em, no mínimo, 50\% (cinquenta por cento) das escolas públicas, de forma a atender, pelo menos, $25 \%$ (vinte e cinco por cento) dos(as) alunos(as) da educação básica) em âmbito local." (BRASIL, 2014).

A análise empreendida tem aproximação no entendimento de que as políticas públicas devem ser entendidas como processo e produto que envolvem articulações entre textos e processos, negociações no âmbito do Estado como espaço em disputa, ancorandose na abordagem do ciclo de políticas proposto por Stephen J. Ball e Mainardes (2011), ao considerar que na análise crítica de políticas públicas importa se preocupar com a análise de contextos, textos e consequências. Assim, é importante considerar os antecedentes históricos, as influências que fizeram com que determinado tema fosse incluído na agenda da política pública; o contexto em que as políticas são formuladas (econômico, social, cultural); as relações com outros textos e políticas; e os efeitos que as políticas podem gerar nas práticas.

Nesse sentido, procuramos atentar para analisar os motivos, os processos desencadeados e os resultados, ainda que parciais, do processo de monitoramento da PEEPA e o alcance de sua Meta 6, ao intencionar a implantação de uma política de educação em tempo integral. Aproximamo-nos da perspectiva da análise do contexto e da produção do texto, pois procuramos destacar o conteúdo da política e as proposições que fundamentaram a política proposta, o que envolveu a análise dos antecedentes históricos, dos objetivos, os valores declarados nos documentos oficiais, bem como as ideias e conceitos explicitados 
nos Planos de Educação, diretrizes, projetos e resoluções publicadas para orientar a política educacional paraense.

Os documentos aqui analisados, especialmente, o Plano Estadual de Educação do estado do Pará/2015, o Plano Estadual de Educação Integral/2014, o Relatório de Monitoramento das Metas do PNE/2016, bem como resoluções e portarias instituídas, assumiram centralidade na perspectiva de que podem expressar a possibilidade de perceber o alcance das metas, em especial, da Meta 6, bem como a efetividade das iniciativas postas em prática para a concretude da política planejada.

Este texto está estruturado em duas seções, além desta introdução e das considerações finais. A primeira traz a discussão conceitual sobre educação em tempo integral nos dois planos estaduais de educação do Pará, de 2010 e de 2015, um breve histórico de experiências levadas à efeito que culminaram na produção de diretrizes teóricometodológicas para a implantação da proposta a partir de 2015; a segunda seção apresenta uma análise específica do Plano Estadual de Educação de 2015 e seu alinhamento à meta 6 do PNE/2014, traz dados de matrícula da rede estadual para contextualizar a tímida expansão do atendimento em tempo integral, destaca no relatório de monitoramento do PEE/PA a diferença entre o planejado e o alcançado até o ano de 2019. Concluímos que os esforços institucionais empreendidos mostram a dificuldade de alcance da meta 6 no estado do Pará.

\section{O TEMPO INTEGRAL NOS PLANOS ESTADUAIS DE EDUCAÇÃO NO PARÁ}

0 debate da oferta de educação em tempo integral no Pará está referendado no processo de constituição de seus dois planos estaduais de educação. Um primeiro, aprovado em 2010, Lei $n^{\circ}$ 7.441, de 2 de julho de 2010, fruto de intensa participação social ocorrida por força da realização de conferências municipais, em 2007, e da Conferência Estadual de 2008 (PARÁ, 2010). Naquele momento, os órgãos do sistema de educação paraenses procuravam sanar uma lacuna, visto que o PNE já estava em vigor desde 2001 e o Pará ainda não tinha o seu Plano Estadual.

Naquele período, o governo estadual não priorizou a elaboração do PEE paraense nem tampouco a implantação e implementação de políticas para a ampliação progressiva da jornada escolar e a expansão da escola de tempo integral na Educação Básica paraense. Essa demora no processo de construção da referida política fez com que o governo do estado do Pará não desse a devida importância para atingir as metas previstas no referido 
PNE/2001, uma vez que, até 2010 - reafirmamos -, não havia nenhum documento oficial que pudesse nortear a construção dessa política no estado.

Entretanto, importa destacar que, antes da aprovação da Lei 7.441/2010 (PEE-PA), já havia no Pará experiências de escolas que ofertavam a educação em tempo integral; essa oferta acontecia por meio do Programa Mais Educação (PME) do governo federal, implantado em 2009 em vários municípios do estado. Nas escolas que aderiram ao PME, os alunos tinham várias atividades no turno complementar, tais como o acompanhamento pedagógico obrigatório para aqueles alunos com baixo rendimento escolar; o Programa também oferecia atividades diversificadas por meio das oficinas curriculares.

As experiências de escolas que ofertavam a educação em tempo integral, por meio da adesão do PME, ocorreram tanto na capital (Belém) quanto em alguns municípios do interior do estado, tais como Abaetetuba, Santarém, Igarapé-Miri, Oriximiná e outros. Cabe mencionar que essas experiências de educação em tempo integral foram atribuídas tão somente ao PME, o que não significa a implantação de uma política de tempo integral; tratava-se de um programa do governo federal, o qual foi encerrado em 2016 e substituído pelo Programa Novo Mais Educação (PNME), programa que também já foi encerrado em 2019.

A oferta da educação escolar em tempo integral, apesar de contemplada de maneira tímida no Plano Estadual de 2010, fez com que a Secretaria de Estado de EducaçãoSEDUC aprovasse, em 2012, duas resoluções que passaram a nortear a política de oferta da escola em tempo integral, documentos que orientaram as ações nas escolas para a implantação do tempo integral, pois, até então, o que ocorria eram adesões das unidades escolares ao PME que ampliavam o tempo de permanência do aluno na escola por meio das atividades diversificadas.

Para o cumprimento das determinações normativas do PEE/2010, a SEDUC, em 2012, se utiliza das Resoluções n 002/2012 (PARÁ, 2012a) e 003/2012 (PARÁ, 2012b) e implanta o piloto do "Projeto Escola de Tempo Integral" em 14 (quatorze) escolas da rede estadual, 9 (nove) delas de Ensino Fundamental, 4 (quatro) de Ensino Médio regular e 1 (uma) de Educação Profissional, todas situadas na região metropolitana de Belém.

Tabela 1 - Relação de Escolas inseridas no Projeto Escola de Tempo Integral/SEDUC/2012

\begin{tabular}{llr}
\hline \multicolumn{1}{c}{ Município } & \multicolumn{1}{c}{ Nome da escola } & \multicolumn{2}{c}{ Total de matrículas } \\
\hline Ananindeua & EEEFM Eneida de Moraes & 112 \\
Belém & EEEF Antonia Paes da Silva & 96 \\
Belém & EEEF Benjamin Constant & 212 \\
Belém & EEEF Dr Carlos Guimarães & 161 \\
Belém & EEEFM Manoel Leite Carneiro & 329 \\
\hline
\end{tabular}




\begin{tabular}{llr}
\hline \multicolumn{1}{c}{ Município } & \multicolumn{1}{c}{ Nome da escola } & Total de matrículas \\
\hline Belém & EEEF Prof Temistocles de Araújo & 172 \\
Belém & EEEF Rui Barbosa & 80 \\
Belém & EEEFF Barão do Rio Branco & 101 \\
Belém & EEEFF Profa Norma Morhy & 145 \\
Belém & EEEFF Ruy Paranatinga Barata & 463 \\
Belém & EEEM Augusto Meira & 362 \\
Belém & EEEM Padre Eduardo & 171 \\
Benevides & EEEF Da Terceira Travessa & 91 \\
Castanhal & EEEFM Maria Das Merces De Oliveira Conor & 57 \\
\hline Total & 14 escolas & 2.552 \\
\hline Fonte: Pará (2014). & &
\end{tabular}

Para a implantação da política de educação em tempo integral, a justificativa utilizada pela SEDUC foi a necessidade do desdobramento da política nacional da Educação Básica, prevista naquela altura no PNE/2001. 0 objetivo dessa ação foi elevar o tempo efetivo do aluno na escola, no sentido de aprimorar a aprendizagem, o fortalecimento da convivência social e a melhoria da qualidade do ensino (PARÁ, 2012a).

De acordo com o relatório do $1^{\circ}$ Ciclo de Monitoramento do PNE/2014 (INSTITUTO NACIONAL DE ESTUDOS E PESQUISAS EDUCACIONAIS ANISIO TEIXEIRA, 2016), para uma escola ser considerada como de tempo integral, ela deveria ter a jornada média diária de 7 horas. Dessa maneira, não se trata de considerar apenas o tempo de permanência do aluno na escola, mas, pressupõe a organização de atividades com base em um projeto pedagógico e não apenas no cumprimento da carga horária. Conforme informações presentes no site oficial da SEDUC, cabe destacar que, das 10 (dez) escolas que foram escolhidas em 2012 para a implementação do Projeto Piloto, apenas 6 (seis) escolas permanecem com este tipo de oferta até o final daquele ano.

No que se refere à Resolução 002/2012, este documento apresentava o indicativo inicial que apontou o quantitativo de dez escolas para atendimento em tempo integral com gradativa expansão na Rede Estadual de Educação; apresentou também a forma de funcionamento que deveria ser adotada, sendo composta de dois turnos: manhã e tarde, com uma jornada de 9 horas diárias e carga horária semanal de 45 aulas. 0 documento previa também critério para a implantação das escolas: 1) espaço físico compatível com o número de alunos e salas de aula para funcionamento em período integral; e 2) intenção expressa da comunidade escolar em aderir ao projeto, ouvido o Conselho Escolar (PARÁ, 2012a).

Além desses critérios para organização da proposta de escola de tempo integral, o documento apresenta alguns princípios norteadores para a elaboração de projetos político- 
pedagógicos a serem construídos pelas escolas. Dentre esses princípios, destaca-se os objetivos do Projeto Escola de Tempo Integral, prescritos no artigo $2^{\circ}$ da Resolução 002/2012:

I - promover a permanência do educando na escola, assistindo-o integralmente em suas necessidades básicas e educacionais, reforçando o aproveitamento escolar, a autoestima e o sentimento de pertencimento; || - intensificar as oportunidades de socialização na escola; II - proporcionar aos alunos alternativas de ação no campo social, cultural, esportivo e tecnológico; IV - incentivar a participação da comunidade por meio do engajamento no processo educacional implementando a construção da cidadania; V - adequar as atividades educacionais à realidade de cada município, desenvolvendo o espírito inovador, criativo e crítico aos educandos. (PARÁ, 2012a, p. 2).

Quanto à estrutura curricular da escola de tempo integral, o currículo da Educação Básica e Profissional incluía ações direcionadas para cinco campos: (1) orientação de estudos; (2) atividades artísticas e culturais; (3) atividades desportivas; (4) atividades de integração social; e (5) atividades de enriquecimento curricular. Apesar de este documento indicar ações que iriam subsidiar inicialmente a estrutura curricular, com vistas a nortear a política de ampliação de tempo integral das escolas escolhidas pela SEDUC, tal documento não apontou um conceito ou um entendimento sobre a composição de tais campos.

A Resolução 002/2012 foi um documento elaborado pela equipe técnica da SEDUC como uma tentativa de apresentar algo que buscasse responder a uma demanda ainda pouco compreendida por ela própria, inclusive, pela falta de diálogo mais aberto com a própria comunidade escolar e suas representações. Notamos que tal documento se limitou a estender o tempo de permanência do aluno na escola, como possibilidade de melhoria no desempenho do aluno no processo de aprendizagem; no entanto, não levou em consideração a precarização das condições de trabalho enfrentadas pela maioria dos docentes, além do sucateamento e a falta de investimentos nas escolas incluídas no projeto de educação em tempo integral do estado.

Outro aporte legal do processo de implantação da política de ampliação do tempo escolar na Rede Estadual de Educação do Pará foi a Resolução 003/2012, que tratou da organização e do funcionamento da escola de tempo integral, cabendo salientar que este documento apresenta maior precisão no que diz respeito à estrutura curricular da referida proposta de escola de tempo integral da SEDUC (PARÁ, 2012b).

Tal documento traz um entendimento sobre os componentes curriculares que integrariam o currículo básico da Educação Básica e Profissional, destacando que os eixos temáticos das oficinas curriculares seriam objeto de aprovação junto ao Conselho Estadual de Educação (CEE-PA), conforme podemos observar: 
Artigo $2^{\circ}$ - A organização curricular em período integral compreenderá o currículo básico do ensino fundamental, médio e profissional e um conjunto de oficinas de enriquecimento curricular. $\S 1^{\circ}$ - Entenda-se por oficina de enriquecimento curricular a ação docente/discente concebida pela equipe escolar em sua proposta pedagógica como uma atividade de natureza prática, inovadora, integrada e relacionada a conhecimentos previamente selecionados, a ser realizada por todos os estudantes, em espaço adequado, na própria unidade escolar ou fora dela, desenvolvida por meio de metodologias, estratégias e recursos didático-tecnológicos coerentes com as atividades propostas para a oficina. (PARÁ, 2012b, p. 1).

Conforme o trecho destacado, observamos que este documento apresenta uma espécie de diretriz que orienta os educadores a implementar o processo educacional proposto para a escola de tempo integral. 0 documento informa que, no currículo básico do Ensino Fundamental, Médio e Profissional, as aulas das disciplinas teriam que seguir a ordem de prioridade das faixas de habilitação/qualificação de docentes. Com relação às aulas das Oficinas Curriculares, a atribuição se organizava na seguinte conformidade, detalhada no art. $4^{\circ}, \S 2^{\circ}$ :

\footnotetext{
a) Orientação para Estudo e Pesquisa: licenciatura plena ou curso de nivel superior equivalente, com as habilitações previstas para as oficinas;

b) Hora da Linguagem: licenciatura plena em Letras com habilitação em Lingua Portuguesa, Língua Estrangeira preferencialmente, ou licenciatura plena em qualquer componente curricular;

c) Informática Educacional: licenciatura plena com formação e conhecimento na área, preferentemente com curso de capacitação desenvolvido pelos NTEs, desde que devidamente comprovado;

d) Experiências em Ciências Humanas, Naturais e Matemáticas: licenciatura plena em Matemática, ou licenciatura plena em Fisica, em Biologia ou em Química ou ainda licenciatura em Ciências Naturais ou Sociais e /ou Humanas plenificada com qualquer habilitação;

e) Língua Estrangeira Moderna: licenciatura plena em Letras, com habilitação no idioma ou com comprovada proficiência adquirida em cursos especializados;

f) Atividades Esportivas e Motoras: licenciatura plena em Educação Fisica;

g) Atividades Artísticas: licenciatura plena em Educação Artística/Arte;

h) Saúde e Qualidade de Vida: licenciatura em Ciências plenificada em Biologia, ou Química, ou Fisica ou em Matemática, ou licenciatura plena em Ciências Biológicas ou ainda licenciatura plena em História Natural;

i) Filosofia: licenciatura plena em Filosofia;

j) Empreendedorismo Social: licenciatura plena em Ciências Sociais. (PARÁ, 2012b, p. 2).
}

0 trecho destacado acima mostra que as Oficinas Curriculares tinham de ser realizadas de acordo com as áreas de conhecimento, exigindo, portanto, a qualificação docente 
de acordo com seu campo de formação. 0 documento esclarece, ainda, que tais Oficinas Curriculares poderiam ser atribuidas a docentes titulares de cargo apenas como carga suplementar de trabalho ou para composição de jornada, exceto as aulas das Atividades Artísticas e Atividades Esportivas e Motoras, que poderiam ser atribuídas, também, para a constituição de jornada dos respectivos titulares de cargo.

Além de esclarecer sobre a organização curricular para as escolas de tempo integral da Rede Estadual de Educação do Pará, o documento informa que as Coordenadorias de Ensino Fundamental, Ensino Médio e Educação Profissional, respeitadas as respectivas áreas de competência, poderiam expedir instruções complementares à presente resolução e, quando necessário, decidir sobre situações cujas especificidades exijam análise casuística.

É importante salientar que a Resolução 003/2012 foi um documento de grande importância para entender como a SEDUC encaminhou sua proposta pedagógica para as escolas que fizeram parte do Projeto Piloto Escola de Tempo Integral. Entretanto, ressaltase que, nem na Resolução 002/2012, nem na Resolução 003/2012, encontramos a presença de um referencial teórico consistente sobre educação em tempo integral que embasasse o diálogo com as escolas, o que compromete seu construto teórico-metodológico, além de atestar um empobrecimento dos referidos documentos.

Também não encontramos estudo sobre a viabilidade dessas resoluções nas escolas que participaram da proposta piloto, o que demandará a realização de outras pesquisas para perceber a sua efetividade nas práticas escolares. Por certo, essas orientações experimentaram uma curta vigência junto à Rede, visto que, em 2014, a SEDUC aprova o Plano Estadual de Educação em Tempo Integral, em 2015, aprova um novo Plano Estadual de Educação, em análise a seguir.

\section{O PLANO ESTADUAL DE EDUCAÇÃO DO PARÁ DE 2015: 0 DIFÍCIL ALINHAMENTO À META 6 DO PNE/2014}

0 segundo Plano Estadual de Educação do Pará, homologado pela Lei n 8.186, em 23 de junho de 2015 (PARÁ, 2015), tem como justificativa a adequação das metas paraenses às novas prerrogativas do PNE/2014, que tornou obrigatória, no prazo de 1 (um) ano, a aprovação de Planos de Educação pelos entes federados subnacionais; o que foi cumprido, sem a mesma mobilização social do período anterior.

A SEDUC optou por apresentar o documento em uma Audiência Pública realizada em 12 de maio de 2015, em meio a um longo período de greve dos professores da rede estadual pelo cumprimento do piso nacional do magistério e por melhores condições de trabalho, uma 
greve que acumulava 3 (três) meses de paralisação, com suspensão de salários, um período tenso, conflituoso e de pouco diálogo governamental. A audiência pública ocorreu em meio a protestos, silenciamentos e interrupção dos debates por parte da representação oficial da SEDUC, mas, mesmo assim, o Plano foi considerado aprovado pelo CEE-PA.

No texto oficial do PEE-PA/2015, há a previsão da oferta da educação em tempo integral. Constatamos na análise da redação aprovada que há muitos pontos convergentes e, por que não dizer, que se apresentam ipsis litteris em relação ao PNE/2014. Isso pode ser verificado, por exemplo, no artigo $2^{\circ}$, que discorre sobre as diretrizes assumidas pelo PEE-PA, fazendo alusão, respectivamente, à melhoria da qualidade da educação e ao atendimento às necessidades de expansão, com padrão de qualidade e equidade, conforme os incisos II e VIII da lei estadual.

Não obstante a similitude das expressões de tempo integral no PEE-PA quando comparado ao PNE/2014 (Lei $n^{\circ} 13.005 / 2014$ ), admitimos a priori que se trata de um conceito, por vezes, apresentado com equívocos metodológicos e, por isso, divergentes, conforme discorreremos a seguir.

Diferente do PNE/2014, o PEE-PA/2015 atribuiu à Meta 6 no estado do Pará um percentual menor de oferta educacional, visto que a meta está descrita como "oferecer educação em tempo integral em, no mínimo, 30\% (trinta por cento) das escolas públicas, de forma a atender, pelo menos, $15 \%$ (quinze por cento) dos(as) alunos(as) da educação básica" - um desafio muito menor do que a determinação nacional.

Contraditoriamente a esta meta percentualmente menor que o estabelecido nacionalmente, o PEE apresenta uma análise situacional que atesta a enorme carência e o atraso desta política no território paraense. 0 documento expressa a necessidade de avançar na construção de propostas exequíveis à realidade, atestando que é possível pensar em modelos de organização de educação integral que atendam às diferentes especificidades da dinâmica social vivida no solo paraense.

Vale destacar que, no texto de apresentação do PEE-PA/2015, credita-se ao PME/2008 o início da oferta do tempo integral na rede estadual de ensino paraense, por meio de três modelos: escola de tempo integral; educação integral; educação integral com parceria institucional. A este respeito, o texto do PEE é bastante incisivo ao constar que a oferta da escolarização em tempo integral depende sobremaneira de parcerias com setores da sociedade civil e ONG's, pois o documento se apoia numa compreensão de que

0 PNE 2014 faculta a implementação das atividades dentro do espaço escolar conforme a disponibilidade da escola, ou fora dele, em espaços distintos da cidade ou do território em que está situada a unidade escolar, mediante a utilização de equipamentos sociais e culturais aí existentes e 
- estabelecimento de parcerias com órgãos ou entidades locais, sempre de acordo com o respectivo projeto político pedagógico. (PARÁ, 2015, p. 62).

Apesar dessa aparente falta de precisão conceitual, o PEE-PA também se referencia nas Diretrizes Curriculares da Educação Básica, Resolução CNE/CEB n 04/2010, para $o$ alcance da meta prevista, a saber:

\begin{abstract}
Art. 12. Cabe aos sistemas educacionais, em geral, definir o programa de escolas de tempo parcial diurno (matutino ou vespertino), tempo parcial noturno, e tempo integral (turno e contra-turno ou turno único com jornada escolar de 7 horas, no mínimo, durante todo o período letivo), tendo em vista a amplitude do papel socioeducativo atribuído ao conjunto orgânico da Educação Básica, o que requer outra organização e gestão do trabalho pedagógico.

$\S 1^{\circ}$ Deve-se ampliar a jornada escolar, em único ou diferentes espaços educativos, nos quais a permanência do estudante vincula-se tanto à quantidade e qualidade do tempo diário de escolarização quanto à diversidade de atividades de aprendizagens.

$\S 2^{\circ} \mathrm{A}$ jornada em tempo integral com qualidade implica a necessidade da incorporação efetiva e orgânica, no currículo, de atividades e estudos pedagogicamente planejados e acompanhados. (BRASIL, 2010, p. 4).
\end{abstract}

As Diretrizes aqui referenciadas e uma série de estudos e pesquisas têm apontado para a necessidade de que o estado assuma a dimensão da educação integral em tempo integral. A referida norma, agora amplamente consolidada pelo PNE e pelos Planos Estaduais e Municipais, preconiza que a proposta educacional da educação integral promova a ampliação de tempos, espaços e oportunidades educativas e o compartilhamento da tarefa de educar e cuidar, sob a coordenação da escola e de seus professores, visando alcançar a melhoria da qualidade da aprendizagem e da convivência social e diminuir as diferenças de acesso ao conhecimento e aos bens culturais, em especial, entre as populações socialmente mais vulneráveis.

As Diretrizes apresentam uma compreensão da educação integral em tempo integral que fundamenta uma perspectiva pedagógica de cunho interdisciplinar que possibilite a superação da fragmentação do processo educativo e a efetiva oferta de uma formação integral. A ampliação da jornada escolar diária poderá ocorrer mediante o desenvolvimento de atividades socioeducativas, com vistas à implementação do acompanhamento sistemático do percurso da aprendizagem, com foco na adoção da pesquisa enquanto princípio educativo, a valorização da cultura e das artes, do esporte e do lazer, das tecnologias da comunicação e informação, da afirmação da cultura dos direitos humanos, da preservação do meio ambiente, da promoção da saúde, entre outras, sejam articuladas aos componentes curriculares e às áreas de conhecimento, às vivências e práticas socioculturais. 
Nos debates mais atuais sobre o tempo da escola, está consagrada a luta por mais tempo e por uma diversidade curricular que possa formar o educando o mais completo possível. No caso da escola pública, também lutamos pelo direito a essa gama de atividades socialmente importantes, mas precisamos atentar para que esse tempo a mais e as atividades nele impostas se construam em um todo integrado, que caminhe na construção crítica dos educandos. (OLIVEIRA; CARDOSO, 2018).

Logo, o PEE-PA, ao adotar uma lógica de educação em tempo integral que não se fará somente na escola, mas, nos espaços comunitários disponíveis para ações em "parceria", reforça uma perspectiva de tempo integral num aspecto de diminuição ou um papel secundário, até mesmo de ausência da escola na condução deste processo - uma concepção limitada do tempo integral, posto que outros espaços sociais podem assumir a tarefa educadora, desresponsabilizando o estado desta ação educativa, o que não é o desejável de uma ação estatal.

Nesta perspectiva, Cavaliere (2009) já discutiu que este modelo de oferta de atividades exteriores ao projeto educativo da escola, se aproxima muito mais da promoção de alunos de tempo integral, ou seja, uma ênfase na oferta de atividades diversificadas em turno alternado para os alunos, a partir da articulação ou parcerias com diversas instituições, do que uma educação de tempo integral a partir de uma ação dirigida pela própria escola. Muitas dessas atividades, por vezes apartadas do projeto pedagógico escolar e da efetiva configuração de educação integral, não promovem a possibilidade da educação integral em tempo integral.

Tal perspectiva se associa a uma forma gerencial da educação pública, articulando parcerias principalmente com organizações sociais em prol da resolução de demandas de que o Estado deveria dar conta, além de ratificar a conexão entre o setor público e o privado, conforme sinaliza Peroni (2013), entre outros estudiosos.

Passando para a análise das estratégias do PEE-PA para o alcance da Meta 6, parcialmente recepcionada pelo estado do Pará, foi definida em duas distintas obrigações: a) oferta de educação em tempo integral em, no mínimo, 30\% das escolas públicas; e b) atender, pelo menos, 15\% dos(as) alunos(as) da educação básica.

Vale destacar que o PEE-PA previu um esforço do atendimento educacional integral em percentual inferior ao estabelecido nacionalmente, o que revela o compromisso menor da política paraense e o aprofundamento da desigualdade de oportunidades e a manutenção da assimetria regional na oferta deste atendimento educacional.

No estado do Pará, em 2015, de um total de 10.341 estabelecimentos de ensino públicos (compreendendo 875 da rede estadual e 9.455 das redes municipais), a Meta 6 
projetada exigiria que, aproximadamente, 3.102 escolas públicas realizassem a oferta pretendida até o final do decênio, o que se configura um grande desafio político e institucional.

Para percebermos a distância que estamos desse alcance, basta tomar como exemplo a Rede Estadual, que, em 2015, ano de aprovação do PEE paraense, possuía um total de 875 escolas estaduais; destas, apenas 14 ofertavam o tempo integral, com um total de 2.12१ matrículas. Observando a meta, o desafio do Pará neste decênio, somente na rede estadual, implica na multiplicação de pelo menos 262 estabelecimentos de ensino que ofertem as 7 horas diárias de trabalho escolar, conforme determina a norma legal.

A Rede Estadual do Pará possui um Plano Estadual de Educação Integral, aprovado no ano de 2012, enquanto uma política oficialmente instituída. Assim, optamos por trazer somente as matrículas da rede estadual, dos anos posteriores à aprovação do PEE-PA, para dimensionar a projeção desta política no âmbito da rede estadual paraense e o quanto estamos distantes do seu efetivo alcance.

Tabela 1 - Número de escolas da rede estadual em tempo integral/ano/matrículas - Ensino Fundamental - Pará

\begin{tabular}{|c|c|c|c|c|}
\hline Ano & $\begin{array}{c}\text { № de Escolas } \\
\text { no Pará }\end{array}$ & $\begin{array}{l}\mathrm{N}^{\circ} \text { de Escolas } \\
\text { (Tempo Integral) }\end{array}$ & $\begin{array}{l}\text { Matrícula no Ensino } \\
\text { Fundamental }\end{array}$ & $\begin{array}{l}\text { Matrículas Ens. Fundamental } \\
\text { (Tempo Integral) }\end{array}$ \\
\hline 2016 & 581 & 11 & 204.527 & 1.690 \\
\hline 2017 & 559 & 10 & 191.889 & 1.652 \\
\hline 2018 & 555 & 10 & 173.413 & 1.760 \\
\hline
\end{tabular}

Fonte: elaborado pelas autoras com base em dados disponiveis no site oficial da SEDUC (GOVERNO DO PARÁ, 2019).

Conforme dados sistematizados na Tabela 1, no ano de 2016, de um total de 581 escolas, apenas 11 ofertaram vagas em tempo integral. No ano de 2017 , observamos um decréscimo de escolas com oferta do Ensino Fundamental na rede estadual, e, destas, apenas 10 oferecem matrículas com tempo integral, o que significa um menor atendimento em relação ao ano anterior. Em 2018, observamos um número ainda menor de escolas estaduais de Ensino Fundamental - somente 555 - e, dentre estas, mantém-se o atendimento em tempo integral em 10 escolas, mas, contraditoriamente, com um universo de matrículas maior do que nos anos anteriores, totalizando 1.760 matrículas em tempo integral.

Aqui guarda uma atenção especial um estudo sobre as causas da diminuição de escolas estaduais com a oferta de matrículas no Ensino Fundamental. 0 próprio PPE/PA 2015, em seu diagnóstico apresenta a necessidade de retomar os processos de municipalização ou mesmo a política de nucleação de escolas nas localidades do campo, política que foi fortemente estimulada pela SEDUC em 2017 (CARMO, 2018), com o consequente fechamento 
de unidades escolares nos municípios paraenses, mas este tema demandará um estudo específico nesta direção.

Entretanto, nosso estudo apresenta um indicativo de que outro fator que pode ter influenciado a diminuição de matrículas em tempo integral pode ser atribuído ao encerramento das atividades do PME no ano de 2016 e sua substituição, no ano seguinte pelo PNME, o que exigiu das escolas novos processos de adesão e adequações às novas diretrizes propostas, deixando um vácuo temporal no credenciamento das escolas no novo programa. Por conseguinte, isso influenciou nas matrículas no ano de 2017.

$\mathrm{Na}$ análise por segmento da Educação Básica, destacando separadamente as matrículas no Ensino Fundamental e no Ensino Médio, percebemos que o distanciamento da meta é ainda mais significativo, o que exigirá firmeza de propósitos e determinação política na destinação de recursos financeiros adequados ao desafio, conforme demostramos nas tabelas 2 e 3 a seguir:

Tabela 2 - Número de escolas da rede estadual, por ano de oferta de matrículas no Ensino Fundamental e Médio em Tempo Integral - Pará

\begin{tabular}{|c|c|c|}
\hline Ano & $\mathrm{N}^{\circ}$ de escolas & $\mathrm{N}^{\circ}$ de matrículas \\
\hline 2016 & 14 & 2.552 \\
\hline 2017 & 27 & 4.831 \\
\hline 2018 & 32 & 6.631 \\
\hline
\end{tabular}

Fonte: elaborado pelas autoras com base em dados disponiveis no site oficial da SEDUC GOVERNO DO PARÁ, 2019).

Como é possível visualizar, o número de escolas e matrículas em tempo integral é irrisório até o ano de 2018 no estado do Pará. Com o PNE aprovado em 2014 e o PEE-PA aprovado em 2015, e decorridos quase cinco anos dos planos e suas metas, se verifica que o esforço da política pública ainda é insignificante diante do enorme desafio traçado. Ainda que, nos três anos analisados (2016 a 2018), o número de escolas tenha praticamente dobrado (de 14 escolas passou a ter 32 escolas com a oferta do tempo integral), apesar do esforço louvável, ainda estamos muito longe de atender plenamente à meta.

No caso da oferta do tempo integral no Ensino Médio, etapa obrigatória e de competência do estado, temos os seguintes dados na Tabela 3. 
Tabela 3 - Número de escolas da rede estadual, por ano, que ofertaram matrículas no Ensino Médio em tempo integral - Pará

\begin{tabular}{|c|c|c|c|c|}
\hline Ano & $\begin{array}{c}N^{0} \text { de Escolas } \\
\text { no Pará }\end{array}$ & $\begin{array}{l}\mathrm{N}^{\circ} \text { de Escolas } \\
\text { (Tempo Integral) }\end{array}$ & $\begin{array}{l}\text { Matrículas no } \\
\text { Ensino Médio }\end{array}$ & $\begin{array}{l}\text { Matrículas Ens. Médio } \\
\text { (Tempo Integral) }\end{array}$ \\
\hline 2016 & 548 & 3 & 320.433 & 862 \\
\hline 2017 & 590 & 17 & 314.452 & 3.179 \\
\hline 2018 & 607 & 22 & 317.126 & 4.781 \\
\hline
\end{tabular}

Fonte: elaborado pelas autoras com base em dados disponiveis no site oficial da SEDUC GOVERNO DO PARÁ, 2019).

Percebe-se que no Ensino Fundamental houve um congelamento de escolas incluídas na política estadual de tempo integral e na etapa do Ensino Médio é onde se registra um esforço maior de implantação do tempo integral, pois o estado saiu de uma oferta em apenas 3 escolas, em 2012, e ampliou para 22 escolas em três anos. Ainda assim, de um total de 607 escolas, apenas 22 realizaram a oferta demandada pela meta, até o ano de 2018. No ano de 2019 o tempo integral se expandiu em mais 8 escolas de ensino médio, totalizando 30 escolas e aumentando para 8.317 matrículas no E. Médio com a oferta do tempo integral (PARÁ, 2020). Tal expansão deve-se também ao Convênio firmado com o Ministério da Educação (MEC) para a implantação do programa Novo Ensino Médio, uma variável nova nesse contexto, que exigirá uma nova fase de investigação e análise.

Percebemos que o estado do Pará vem experimentando de forma lenta e gradual a implementação do tempo integral em paralelo ao regime de tempo parcial. Nesse contexto, a importância do aporte de recursos, infraestrutura adequada, elaboração de um projeto educativo de oferta de educação integral, a consolidação de uma proposta curricular e o reordenamento das redes de ensino são exigências básicas para a ampliação da oferta da educação integral, com a finalidade de aumento de matrículas.

Após essa breve contextualização, passamos agora a análise das estratégias apresentadas no PEE-PA, para analisar sua pertinência no plano anunciado. São, em síntese, as seguintes:

6.1) promover, com o apoio da União, a oferta de educação básica pública em tempo integral, por meio de atividades de acompanhamento pedagógico e multidisciplinares, inclusive culturais e esportivas, de forma que o tempo de permanência dos(as) alunos(as) na escola, ou sob sua responsabilidade, passe a ser igual ou superior a 7 (sete) horas diárias durante todo $\circ$ ano letivo, com a ampliação progressiva da jornada de professores em uma única escola;

6.2) desenvolver, em regime de colaboração, programa de construção de escolas com padrão arquitetônico e mobiliário adequados para atendimento em tempo integral, prioritariamente em comunidades que se encontram em situação de vulnerabilidade social, de acordo com as leis vigentes; 
6.3) participar de programa nacional de ampliação e reestruturação das escolas públicas, por meio da instalação de quadras poliesportivas, laboratórios, inclusive de informática com acesso à internet, espaços para atividades culturais, bibliotecas, auditórios, cozinhas, refeitórios, banheiros e outros equipamentos;

6.4) fomentar a articulação da escola com os diferentes espaços educativos, culturais e esportivos e com equipamentos públicos, como centros comunitários, bibliotecas, praças, parques, museus, teatros, cinemas e planetários;

6.5) oferecer, no âmbito de suas competências, cursos de formação de recursos humanos para a atuação na educação em tempo integral, na vigência deste PEE;

6.6) promover a articulação da escola com os diferentes espaços educativos, culturais e esportivos e com equipamentos públicos como centros comunitários, bibliotecas, praças, parques, museus, teatros, cinemas e planetários;

6.7) atender, no âmbito de sua competência, com padrão de qualidade, as escolas do campo e de comunidades indígenas e quilombolas, na oferta de educação em tempo integral, com base em consulta prévia e informada às comunidades, considerando as peculiaridades locais;

6.8) garantir, no âmbito de sua competência, a educação em tempo integral para pessoas com deficiência, transtornos globais do desenvolvimento e altas habilidades ou superdotação na faixa etária de 4 (quatro) a 17 (dezessete) anos, assegurando atendimento educacional especializado complementar e suplementar ofertado em salas de recursos multifuncionais da própria escola ou em instituições especializadas;

6.9) garantir, no âmbito de sua competência, a efetivação da educação integral de tempo integral na proposta pedagógica da escola, de modo que promova uma nova qualidade da educação, com a permanência dos estudantes na escola, direcionando a expansão da jornada para o trabalho educativo escolar, articulando as dimensões cognitivas, culturais, artísticas, estéticas, recreativas, lúdicas e esportivas;

6.10) promover em regime de colaboração, a oferta de educação básica pública em tempo integral, por meio de orientações de estudos e leituras e atividades multidisciplinares, inclusive, culturais e esportivas, de forma que o tempo de permanência dos alunos na escola, ou sob sua responsabilidade, passe a ser igual ou superior a sete horas diárias durantes todo o ano letivo, com a ampliação progressiva da jornada de professores em uma única escola. (PARÁ, 2015, p. 67-68).

Uma análise que salta aos olhos é que as estratégias declaradas estão fortemente vinculadas ao aporte dos recursos da União, apostando na efetividade da relação de colaboração federativa ou no aporte de outras instâncias de financiamento, para dar conta das condições de infraestrutura mínimas das escolas, tais como construção de novos espaços escolares ou adequação dos já existentes, adequação dos equipamentos escolares, como quadras, laboratórios de informática, bibliotecas, mobiliários, entre outros, que se tornam importantíssimos para a ampliação da jornada escolar. 
Nas estratégias registradas no PEE-PA, ${ }^{3}$ não percebemos nenhum aporte de recursos do tesouro estadual para prover a política dos insumos necessários para sua implantação com qualidade. Ou seja, o governo estadual não anuncia nenhuma iniciativa com recursos próprios para prover as escolas das condições mínimas necessárias para a política do tempo integral. Todas as estratégias dessa natureza apontam para a relação de colaboração, participação nos programas federais, o custeio pela União, parcerias com a sociedade, entre outras.

Entretanto, apesar de não estar registrado no PEE, no contexto deste período da política o Governo do Estado celebrou, em 2013 contrato com o BID (Banco Interamericano de Desenvolvimento) para o financiamento do Pacto pela Educação no Pará. No Pacto, foi previsto o investimento de, aproximadamente, $R \$ 351$ milhões na rede estadual até 2017; e dentre suas metas está a expansão da oferta da educação em tempo integral (QUEIROZ, 2018). Possivelmente, este empréstimo internacional não foi citado no texto do PEE para não o vincular o uso desses recursos a nenhuma de suas metas, como este não fizesse parte do orçamento que a Secretaria estadual poderia dispor para o alcance das mesmas.

Apesar dessa pseudo-ausência do tesouro estadual no custeio da educação pública paraense, há que se registrar algumas intenções interessantes nas estratégias, tais como: a formação de pessoal para entender os princípios e fundamentos da política de tempo integral; a necessária formação de professores e a implantação da jornada única, uma luta histórica dos educadores; a extensão da proposta de tempo integral para as escolas do campo e de comunidades indígenas e quilombolas, bem como para pessoas com deficiência, transtornos globais do desenvolvimento e altas habilidades ou superdotação. Apesar do registro, ressaltamos que não há no PEE-PA qualquer referência ao financiamento dessas ações, prazos ou encaminhamentos para a garantia dessa oferta.

As estratégias são pertinentes, fundantes e necessárias, mas, quanto à realização da meta, a ficar na dependência dos recursos da União, há forte tendência ao seu não alcance, vista a situação mais recente de contingenciamentos orçamentários por parte da União, na aprovação da Proposta de Emenda Constitucional (PEC) 95/2016, limitando os gastos públicos para os próximos 20 anos. Tais medidas impedem o alcance efetivo da meta e a garantia de uma escola pública de tempo integral de qualidade para as crianças e jovens paraenses.

Os dados em análise neste artigo têm por base os relatórios do $1^{\circ}$ e $2^{\circ}$ Ciclo de Monitoramento do PNE/2014 do Inep/MEC (2016 e 2018) e os dados oficiais da Rede Estadual publicados no site da SEDUC (2019/2020), conforme especificado em cada quadro ou tabela apresentada. 


\section{CONSIDERAÇÕES FINAIS}

Procuramos analisar a concepção de educação/escola de tempo integral que fundamenta o Plano Estadual paraense, bem como os processos instituídos que colaboram para a materialização do alcance da Meta 6 estabelecida no PNE/2014. Percebemos nesse estudo dos planos de educação do Pará que as possibilidades de efetivação da escola de tempo integral no estado, estão marcadas por dificuldades de ordem conceitual, metodológicas e de falta de prioridade no financiamento público.

Percebemos que no aspecto metodológico a implantação da política de escola de tempo integral não avançou ao que já se tinha experimentado na rede, foi inspirada no Programa Mais Educação/MEC//2008, o PEE/PA/2015 estabelecendo uma proposta de atendimento em atividades diversificadas que se delineou em três desenhos de oferta do tempo integral, oferecendo atividades socioeducativas em turno complementar ao turno de atividades curriculares. Ou seja, a política proposta não trouxe qualquer inovação conceitual ou metodológica na sua efetivação, tão pouco alocou-se recursos financeiros adicionais para fazer frente às demandas desta política.

Acrescente-se a isso o desacordo do PEE-PA/2015 com a meta proposta pelo PNE/2014, ao estabelecer como meta a oferta de tempo integral em apenas $30 \%$ de escolas e $15 \%$ dos alunos da Educação Básica, um percentual muito menor do que o estabelecido nacionalmente. $E$ ainda assim, com esse percentual menor, os dados dos relatórios de monitoramento do PNE publicados pelo MEC/Inep de 2015 a 2018 atestam que apenas $13,4 \%$ de escolas paraenses (considerando as redes municipais e estadual) apresentaram matrículas em tempo integral, revelando enorme distância do possível alcance da Meta 6 até o final de vigência dos Plano. Lamentavelmente os dados aqui apresentados e os documentos analisados também atestam o descaso do estado com a política educacional proposta e com o direito de todos a conviver em uma escola integral em tempo integral.

Percebemos que o tempo lento do governo paraense em promover ações para o alcance de suas metas esteve circunscrito nas determinações de ordem financeira, por isso é fundamental não perder de vista que as políticas educacionais (e seus Planos) como expressão da materialização da ação do Estado/Governo, são mediadas pelo contexto social mais amplo, pelas novas regulações, centralidade de financiamento, formas de avaliação e modelos de gestão, nem sempre em resposta às demandas educacionais, mas, certamente, resultantes de macro processos que impactam as prioridades das políticas públicas (DOURAD0, 2020).

Por fim, vale ressaltar que uma política educacional é, portanto, historicamente produzida e tem, nas instituiçães educativas, lócus de produção e de apropriação do saber, 
espaços em que as políticas, a gestão e os processos organizam-se, coletivamente ou não. Este processo é sempre resultante das condições objetivas e, também do compromisso de diferentes sujeitos sociais, incluindo gestores e professores, estudantes, pais, comunidade em geral. É por isso que a pauta pela valorização da escola pública, do Plano Nacional e dos planos subnacionais como "epicentro" das políticas educacionais (DOURAD0, 2017) e do necessário alcance de suas metas, faz-se necessário e continuará a alimentar nossos debates no campo das políticas públicas.

\section{REFERÊNCIAS}

BALL, S. J.; MAINARDES, J. (org.). Políticas educacionais: questões e dilemas. São Paulo: Cortez, 2011.

BRASIL. Lei n. 13.005, de 25 de junho de 2014. Aprova o Plano Nacional de Educação - PNE e dá outras providências. Diário Oficial da União, Brasília, DF, 26 jun. 2014. Disponível em: http://www.planalto.gov. br/ccivil_03/_Ato2011-2014/2014/Lei/L13005.htm. Acesso em: 10 nov. 2019.

BRASIL. Resolução CNE/CEB n. 4, de 13 de julho de 2010. Define as Diretrizes Curriculares Nacionais Gerais para a Educação Básica. CNE. Brasília, DF: MEC, 13 jun. 2010.

CARMO, E. S. A Nucleação das Escolas do Campo no Pará: limites, contradições e possibilidades na garantia do direito à educação. Tese (Doutorado em Educação) - Programa de Pós-Graduação em Educação, Universidade Federal do Pará, Belém, 2018.

CAVALIERE, A. M. V. Escola de tempo integral versus alunos em tempo integral. Em Aberto, Brasília, DF, v. 22, n. 80 , p. 51-63, 2009.

DOURADO, L. F. (org.). PNE, Políticas e Gestão da Educação: novas formas de organização e privatização. Brasília, DF: Anpae, 2020.

DOURADO, L. F. Plano Nacional de Educação: o epicentro das políticas de estado para a educação brasileira. Goiânia: Editora da Imprensa Universitária/ANPAE, 2017.

GOVERNO DO PARÁ. Secretaria de Educação. Disponível em: http://www.seduc.pa.gov.br/portal/escola/consultamatrícula/relatório. Acesso em: 5 ago. 2019.

INSTITUTO NACIONAL DE ESTUDOS E PESQUISAS EDUCACIONAIS ANÍSIO TEIXEIRA. Diretoria de Estudos Educacionais. Relatório do $1^{`}$ Ciclo de Monitoramento das metas do PNE: biênio 2014-2016. Brasília, DF: INEP, 2016. Disponivel em: http://portalinep.gov.br/documents. Acesso em: 10 mar. 2020.

OLIVEIRA, N. C. M.; CARDOSO, C. S. Educação integral elm) tempo integral no Município de Belém: momentos e movimentos. In: FEREIRA, A. G.; BERNARDO, E. S.; MENEZES, J. S. S. Políticas e gestão em educação em tempo integral: desafios contemporâneos. Curitiba: CRV, 2018. p. 253-276. 
PARÁ. Lei n. 7.441, de 2 de julho de 2010. Aprova o Plano Estadual de Educação e dá outras providências. Diário Oficial do Estado do Pará, Belém, PA, v. 120, n. 31.707, p. 1-12, 13 jul. 2010. Disponível em: http://www.cee.pa.gov.br/.pdf. Acesso em: 10 jan. 2020.

PARÁ. Lei n. 8.186, de 23 de junho de 2015. Aprova o Plano Estadual de Educação - PEE e dá outras providências. Diário Oficial do Estado do Pará, Belém, PA, v. 125, n. 32.913, p. 1-32, 24 jun. 2015. Disponivel em: http://simec.mec.gov.br/sase/sase. Acesso em: 10 jan. 2020.

PARÁ. Resolução n. 002, de 24 de abril de 2012. Dispõe sobre o projeto de escola de tempo integral. Diário Oficial do Estado do Pará, Belém, PA, 25 abr. 2012a.

PARÁ. Resolução n. 003, de 24 de abril de 2012. Dispõe sobre a organização e o funcionamento da escola de tempo integral. Diário Oficial do Estado do Pará, Belém, PA, 25 abr. $2012 b$.

PARÁ. Secretaria da Educação. Relatório de acompanhamento da implantação do Ensino Médio em Tempo Integral. Belém: [s. n.], 2020.

PARÁ, Secretaria de Estado de Educação. Plano Estadual de Educação Integral para o Ensino Fundamental da Rede Estadual de Ensino do Pará, Belém: [s. n., 2014.

PERONI, V. M. V. (org.). Diálogos sobre as redefinições no papel do Estado nas fronteiras entre o público e o privado na educação. São Leopoldo: Oikos, 2013.

QUEIROZ, L. M. G. Políticas de educação e terceiro setor: o pacto pela educação no Pará. 2018. Tese (Doutorado em Educação) - Programa de Pós-Graduação em Educação, Instituto de Ciências da Educação, Universidade Federal do Pará, Belém, PA, 2018.

Endereço para correspondência: Avenida Pedro Alvares Cabral, Pass. Pinto Marques, 34, Marambaia, 66615-880, Belém, Pará, Brasil; neycmo@ufpa.br 